\title{
On estimating tropical forest carbon dynamics in Papua New Guinea
}

\author{
Jane Bryan • J. B. Kirkpatrick • P. L. Shearman • J. Ash
}

Received: 25 July 2010 / Accepted: 23 January 2011 / Published online: 1 March 2011

(C) The Author(s) 2011. This article is published with open access at Springerlink.com

One of the few initiatives to address ongoing global warming that did not completely stall at the UNFCCC climate change negotiations was the reduction emissions from deforestation and forest degradation (REDD). REDD has a focus on the forests of the tropics. Unfortunately forest mensuration in most tropical countries has been inadequate to accurately determine forest carbon stocks, much less the effects of land use and changes in land use on them (Houghton et al. 2009; Bryan et al. 2010a). Whilst tropical logging is known to be widespread, the exact areas of tropical forest subject to logging have not been accurately mapped (Asner et al. 2009) or mapped with sufficient regularity to provide adequate data on the areas subject to this activity. Biomass losses due to logging have usually been derived from limited plot data, or derived via various models from estimates of regional biomass and timber extraction volumes (Houghton et al. 2009) and thus

Handling Editor: Erwin Dreyer

J. Bryan $(\bowtie) \cdot$ J. B. Kirkpatrick

School of Geography and Environmental Studies,

University of Tasmania,

Private Bag 78,

7001 Hobart, TAS, Australia

e-mail: jebryan@utas.edu.au

J. Bryan · P. L. Shearman

Biology Department, UPNG Remote Sensing Centre,

University of Papua New Guinea,

P.O. Box 320, Waigani,

Port Moresby, Papua New Guinea

P. L. Shearman · J. Ash

School of Botany and Zoology,

The Australian National University,

Linnaeus Way, ANU,

0200 Canberra, ACT, Australia encapsulate considerable uncertainty. For these reasons the carbon impact of tropical logging remains an open question, and one that needs to be closed before any international institutional arrangement considers promoting forms of timber extraction as a tool for controlling carbon emissions. Here, we examine the current state of forest carbon research in Papua New Guinea (PNG) to illustrate the problems that can arise by developing forest management policy prematurely from incomplete forest research.

The question of the effects of logging on carbon stocks in Papua New Guinea has been addressed by Shearman et al. (2008, 2010) and Bryan et al. (2010a), who concluded that the available data were inadequate to derive accurate conclusions on the quanta involved. It has been most recently addressed by Fox et al. (2010) who are confident that their analysis of permanent sampling plots (PSPs) 'provides a sound basis for estimating $\mathrm{C}$ dynamics associated with LULUCF' (p. 7), LULUCF being land use, land use change and forestry. In the present paper, we examine the attributes of data that would provide such a sound basis, examine the data of Fox et al. (2010) in this context, and comment on the possible political implications of accepting the type of data used by Fox et al. (2010) as valid in the context of REDD.

To understand the effects of changing the manner in which forests are used or managed on carbon balances, data are needed on stocks and flows. The starting point is to understand the carbon stocks in forests that have not been subject to human modification within a timeframe relevant to rates of regeneration. As Bryan et al. (2010a) and Fox et al. (2010) emphasise, confidence in this outcome requires adequate unbiased sampling of forests undisturbed by humans and extrapolation of the results of this sampling using accurate spatial data layers representing the different types of undisturbed forest. 
A first step in understanding the magnitude of flows related to changes in land use is to measure the changes in carbon stocks that occur as a result of those changes. The ideal experimental design for this purpose is before-aftertreatment-control. This design allows changes that are the results of other factors than the disturbance to be identified and separated from the treatment effects. Strong conclusions can also be drawn from adequately replicated pairs of samples, in which one of the pair has been disturbed and the other of the pair remains undisturbed. The validity of this approach rests on the pre-disturbance similarity of each of the pairs, which cannot be exactly known, but can be deduced from underlying environmental conditions or evidence such as pre-disturbance forest structure shown on aerial photographs or satellite imagery. With sufficient replication, uncertainties associated with deduction can be reduced. A third weaker approach, using stratified random sampling of both disturbed and undisturbed forests, makes the deduction of initial similarity more difficult, but some degree of confidence can be achieved with strong environmental stratification. The use of data from samples that have been taken for other reasons than the calculation of the effects of disturbance may also give some indication of the magnitude of the disturbance effect if the data set can be pruned to ensure a high degree of environmental similarity between disturbed and undisturbed plots, and if any biases in plot location can be reasonably assumed to be constant between control and treatment.

The Papua New Guinea data set used by Fox et al. (2010) consists of 115 selectively logged 1-ha PSPs and 10-12 (different figures are given in different parts of the paper) unlogged 1-ha PSPs. While Fox et al. (2010) recognise the gross inadequacy of their primary forest sample, they present a mean and standard deviation for lower montane primary forest for a sample of two, and for lowland primary forest for a sample of ten, in a comparison with the logged plot data set, and speculate that the low mean figures for carbon in the PSP primary forest data might be due to a higher degree of disturbance in PNG rainforests than that elsewhere. However, published carbon data from a further 22 unlogged forest sites from across PNG (Bryan et al. 2010a) suggests carbon stocks may be comparable or higher than unlogged rainforest elsewhere in the tropics. Fox et al. (2010) acknowledge that the 10-12 unlogged forest plots were located close to roads and villages, and consequently might have a prior history of disturbance, and Bryan et al. (2010a) acknowledge a likely bias towards high biomass forests. The only conclusion that can confidently be drawn from these two studies given the small sample is that undisturbed rainforest carbon stocks in PNG are locally highly variable, a conclusion reinforced by recent research (Bryan et al. 2010b). It is not yet possible to draw conclusions about unlogged rainforest carbon stocks in PNG without conducting many more measurements according to purpose-designed unbiased sampling regimes.

The original purpose of the 115 PSPs in logged forest was to monitor the rate of recovery of timber stocks after logging. No pre-logging measurements of carbon stocks, harvest intensity, or logging practices were reported from these sites. Fox et al. (2010) state that, despite attempts to achieve randomness in the location of PSPs, there may have been some plot selection bias towards better stocked forest, and away from both degraded forests, and those that exhibited little potential for forestry, but that the size of plots may have moderated this bias. This possible bias is of relatively small import for the purposes of monitoring sitespecific timber stock recovery, but it is critical for the determination of carbon losses associated with logging, determination of resequestration rates and the capacity to generalise about PNG secondary forests. Carbon stock recovery after logging is strongly related to harvest intensity, initial carbon stocking, the degree of logging damage, logging practices and post-logging silviculture or disturbances (Putz et al. 2008; Bryan et al. 2010b). In the absence of adequate and comparable PSP data from unlogged forest, or pre-logging measurements, or measurements of logging damage or intensity, the effects of logging on carbon stocks cannot be accurately determined.

The PSPs located in logged forest used by Fox et al. (2010) were all established within 4 years after logging occurred and their maximum age is two decades, making them unrepresentative of disturbed forest as a whole, so of little use in calculating carbon stocks in disturbed forests at any particular time, unless it is assumed that the effects of logging are the same as those of other disturbances that initiate secondary succession. We are not aware of any work that supports this assumption in PNG, and there is substantial evidence that industrial tropical logging in fact differs in location, intensity of biomass damage, soil damage, species removal, areal extent of disturbance, frequency of recurrence of disturbance and post disturbance growth trajectory from other forms of disturbance (Putz et al. 2000; Sist et al. 2003; Sist and Brown 2004; Asner et al. 2006, 2009; Bryan et al. 2010b). The temporal data from these plots could have been used to gain an indication of change in carbon storage over the two decades that have elapsed since logging, but the approach adopted was to analyse an average of all measurements, which Fox et al. (2010) argue, gives a good measure of carbon stocks in New Guinean secondary forests. However, temporal variation in establishment and remeasurement of PSPs, strong temporal variation in the area of forest logged (Shearman et al. 2009) and the variability in intensity of logging in both space and time combine to make the carbon quanta for secondary forest presented by Fox et al. (2010) of doubtful accuracy, even just for logged forests and even just for the last 20 years. Additionally, logged forest that 
has undergone repeated harvests is not represented in the PSPs. Worryingly, logging of previously logged forests is now becoming increasingly common, to the extent that it should now be included in revised assessments of carbon releases from the sector.

The logged forest PSPs are appropriate for monitoring sitespecific recovery in timber stocks over time after the first commercial harvest of primary forest. That is the purpose for which they were designed and publication of this data would have been a valuable contribution to our understanding of forest ecology. However the PSPs alone do not provide an adequate measure of carbon stocks in unlogged forest, carbon losses associated with logging, nor carbon stocks in forests disturbed by processes other than an initial harvest undertaken by an industrial logging operation.

An associated problem is that Fox et al. (2010) excluded measurements where post-logging fire or other disturbances such as incursions by shifting cultivators had substantially reduced residual biomass because 'the high rates of tree mortality resulted in declines in forest $\mathrm{C}$ that skewed the analysis of unaffected measurements'. The arbitrary removal of low biomass data does raise the concern of a systematic bias in the approach that may have lead to overestimating the biomass of logged forests. In a recent paper that shares a common author with Fox et al. (2010), it was argued that post-logging fire and incursions into logged forest by agriculturalists was not a significant problem in PNG (Filer et al. 2009), yet Fox et al. (2010) present, then exclude contradictory data. Consistent with the measurements presented by Fox et al. (2010), a long-term forest change analysis of PNG found that burning of logged forest and subsequent deforestation is indeed a major issue in $\mathrm{PNG}$, although customary land tenure has prevented human incursion into logged forest from being widespread (Shearman et al. 2009, Shearman et al. 2010). Additionally, it reported that the older a logging concession is in PNG, the greater the proportion of the logged area that is likely to be converted (Shearman et al. 2008, 2010). Post-logging deforestation does not plateau at $10-15 \%$ of the logged area as would be expected if damage was restricted to the construction of roads and log landings. Rather, it continues to increase over time and in many areas continues for decades after logging has ceased. This is probably due initially to the post-logging death of residual trees, but later driven by a synergistic mix of repeated logging, the incursion of local people, fires and the later conversion for other uses - just as Fox et al. (2010) have detected in the PSPs. As approximately $10 \%$ of the logged forest PSP measurements show biomass stocks sufficiently reduced as a result of secondary disturbance factors to be excluded, does this not suggest that regional or provincial estimates of secondary forest biomass stocks should reflect this? We agree that the carbon dynamics of logged forest which has undergone secondary disturbance should, in addition, be reported separately from that of logged forest which has not undergone secondary disturbance. However, it is clear that secondary disturbance of logged forest is sufficiently widespread in PNG that excluding 'the high rates of tree mortality' and 'declines in forest $\mathrm{C}$ ' associated with secondary disturbance of logged forest results in an overestimate of provincial biomass stocks in logged forest, and underestimates the carbon reductions associated with disturbance.

The rationale that underlies the study of Fox et al. (2010) is that secondary tropical forests, such as those that result from logging, are so extensive, and in such a rapid state of expansion, that it is important to know how they act as carbon stores and sinks for REDD. If logged forests are on a rapid path to equal or greater levels of carbon storage than the undisturbed forests, as an uncritical perusal of the results of Fox et al. (2010) might suggest, then logging of tropical forests could be argued to be carbon neutral. Whether recovery of carbon stocks was rapid or not, or complete or not, as long as the trend after logging was positive which it may not be, especially given the collateral effects of logging on deforestation rates (Shearman et al. 2009) and secondary disturbances also detected by Fox et al. (2010), global carbon capture could be argued to be increased by postponing repeat logging operations. Both these options allow for the continuation of a logging industry based on tropical forests, with the second option raising the possibility of both logging and compensation from the developed world for not logging, in the same forests. Acceptance of the hypothesis put forward by Fox et al. (2010) that the primary tropical forests of Papua New Guinea have low carbon stocks because of a high degree of ongoing natural disturbance and past disturbance by shifting cultivators could reduce any urgency for governments to take strong action to prevent any further incursions of logging into primary forest. After all, why leave fire, flood, drought, tempest and villagers to destroy trees when they could be profitably salvaged before the event?

In Papua New Guinea, the existence or not of low carbon stocks in primary rainforest, the causes of low carbon stocks (if they exist), the carbon stores in disturbed and undisturbed forest, the effects of non-logging related disturbance on carbon stores, and the effects of logging on carbon stores are still open questions. They need to be closed before any consideration of international institutional arrangements that could, in extremis, reward tropical forest concessionaires or their host governments simultaneously for both carbon capture and continued logging.

In PNG, like in most tropical countries there is a dearth of knowledge on the growth rates of individual tree species, far less an understanding of the recovery times of degraded forests. It is to be hoped that analysis of PSP data can start to fill this gap. If it cannot, then alternative and perhaps novel research approaches will be needed. Until we have 
further data on this topic it is likely that the notion that these forests can be logged at current DBH limits on a 'sustained yield' basis on a 35-year rotation will be retained-when it is clear to all but the most casual observers that it is not sustainable. The forests of PNG are clearly highly heterogenous in terms of their species composition and biomass, and we are still a long way from documenting this variability far less explaining it. We suggest that future work is focussed on landscape-scale assessments employing unbiased, stratified sampling with well-documented measurement techniques encompassing a key range of environmental gradients.

While further research is clearly needed to reduce these uncertainties, our knowledge is sufficient to know that industrial logging results in substantial carbon emissions - in PNG, a minimum of perhaps $30 \%$ of sequestered carbon is released by a first cutting cycle in operations largely complying with the laws (Bryan et al. 2010b). Over following cutting cycles, biomass stocks are further reduced. There is ample scope for the PNG Government and landowners to work to maintain or increase stocks in degraded forests, and perhaps benefit from doing so via carbon financing, but this would appear to be unethical while primary forests continue to be allocated to unsustainable logging operations.

Open Access This article is distributed under the terms of the Creative Commons Attribution Noncommercial License which permits any noncommercial use, distribution, and reproduction in any medium, provided the original author(s) and source are credited.

\section{References}

Asner GP, Broadbent EN, Oliveira PJC, Keller M, Knapp DE, Silva JNM (2006) Condition and fate of logged forests in the Brazilian Amazon. Proc Natl Acad Sci USA 34:12947-12950
Asner GP, Keller M, Lentini M, Merry F, Souza C Jr (2009) Selective logging and its relation to deforestation. In: Keller M, Gash J, Silva Dias P (eds) Amazonia and Global Change (Geophysical Monograph). American Geophysical Union, Washington DC

Bryan JE, Shearman PL, Ash J, Kirkpatrick JB (2010a) Estimating rainforest biomass stocks and carbon loss from deforestation and degradation in Papua New Guinea 1972-2002: Best estimates, uncertainties and research needs. J Environ Manage 91:995-1001

Bryan J, Shearman PL, Ash J, Kirkpatrick J (2010b) Impact of logging on above ground biomass stocks in lowland rainforest, Papua New Guinea. Ecol Appl 20:2096-2103

Filer C, Keenan RJ, Allen BJ, McAlpine JR (2009) Deforestation and forest degradation in Papua New Guinea. Ann For Sci $66: 813$

Fox JC, Yosi CK, Nimiago P, Oavika F, Pokana JN, Lavong K, Keenan R (2010) Assessment of aboveground carbon in primary and selectively harvested tropical forest in Papua New Guinea. Biotropica 42(4):410-419. doi:10.1111/j.17447429.2009.00617.x

Houghton RA, Hall F, Goetz S (2009) Importance of biomass in the global carbon cycle. J Geophys Res 114:G00E03

Putz FE, Dykstra DP, Heinrich R (2000) Why poor logging practices persist in the tropics. Conserv Biol 14:951-956

Putz FE, Sist P, Fredricksen T, Dykstra D (2008) Reduced-impact logging: challenges and opportunities. For Ecol Manage 256:1427-1433

Shearman PL, Bryan JE, Ash J, Hunnam P, Mackey B, Lokes B (2008) The state of the forests of Papua New Guinea. Mapping the extent and condition of forest cover and measuring the drivers of forest change in the period 1972-2002. University of Papua New Guinea, 2008

Shearman PL, Bryan JE, Ash J, Mackey B, Lokes B (2010) Deforestation and degradation in Papua New Guinea: a response to Filer and colleagues, 2009. Ann For Sci 67:300

Shearman PL, Ash J, Mackey B, Bryan JE, Lokes B (2009) Forest conversion and degradation in Papua New Guinea 1972-2002. Biotropica 41:379-390

Sist P, Brown N (2004) Silvicultural intensification for tropical forest conservation: a response to Fredericksen and Putz. Biodivers Conserv 13:2381-2385

Sist P, Fimbel R, Sheil D, Nasi R, Chevallier M (2003) Towards sustainable management of mixed dipterocarp forest of South-east Asia: moving beyond minimum diameter cutting limits. Environ Conserv 30:364-374 